\title{
Correction to: New treatment strategy for severe heart failure: combination of ventricular assist device and regenerative therapy
}

\author{
Keitaro Domae $^{1} \mathbb{D} \cdot$ Shigeru Miyagawa $^{1} \cdot$ Koichi Toda $^{1} \cdot$ Yoshiki Sawa $^{1}$
}

Published online: 18 August 2020

(c) The Japanese Society for Artificial Organs 2020

\section{Correction to: Journal of Artificial Organs

$$
\text { https://doi.org/10.1007/s10047-020-01185-w }
$$

In the original publication of the article, the following description was missed in the footnote and it has been given in this correction.

This review was created based on a translation of the Japanese review written in the Japanese Journal of Artificial Organs in 2016 (Vol. 45, No. 1, pp. 58-61).

Publisher's Note Springer Nature remains neutral with regard to jurisdictional claims in published maps and institutional affiliations.

The original article can be found online at https://doi.org/10.1007/ s10047-020-01185-w.

Yoshiki Sawa

sawa-p@surg1.med.osaka-u.ac.jp

1 Department of Cardiovascular Surgery, Graduate School of Medicine, Osaka University, 2-2 Yamada-oka, Suita, Osaka 565-0871, Japan 